\title{
System Estimates of Potential Output and the NAIRU
}

\author{
Mikael Apel , Per Jansson* \\ Economics Department, Sveriges Riksbank, S-103 37 Stockholm, Sweden
}

September 1997

\begin{abstract}
This paper proposes a new approach for estimating potential output and the NAIRU. The methodology models these key unobservable economic variables as latent stochastic trends within a trivariate system of observables comprising information on unemployment, GDP, and inflation. Identification is achieved through the use of a standard version of Okun's law and a Phillips curve. The performance of the procedure is investigated using Swedish quarterly data covering the time period 1970:1-1996:3.
\end{abstract}

Keywords: Kalman filter; NAIRU; Okun’s law; Phillips curve; Potential output; Structural time-series models; Unobserved components models.

JEL classification: C32, E32.

* We would like to thank Hans Dillén, Stefan Palmqvist, Lars E. O. Svensson, and Anders Vredin for comments. The views in this paper are those of the authors and do not necessarily reflect those of Sveriges Riksbank. 


\section{Introduction}

The closely related concepts of the NAIRU (Non-Accelerating Inflation Rate of Unemployment) and potential output are central to the conduct of both monetary and fiscal policy. The NAIRU is the unemployment rate that is consistent with a constant rate of inflation, and deviations of unemployment from the NAIRU are associated with deviations of the level of output from its potential level. Thus, theoretically, if policy-makers succeed in setting the actual unemployment rate equal to the NAIRU the economy will be producing at its maximum level of output without inflationary pressure. ${ }^{1}$

After some years of neglect, potential output and the NAIRU have drawn renewed attention as important topics of research in economics. The main reason for the temporary neglect of the concepts has not been that economists, during some particular period of time, did not acknowledge their significance, but rather that the techniques available for estimating them have been too simplistic and mechanical, and thus could be given no meaningful economic interpretation. However, recent research in time-series analysis has produced methods that have turned out to be useful for the purposes of estimating potential output and the NAIRU. One class of models which seems particularly promising is generally termed STM (Structural Time-series Models) or UC (Unobserved Components) and was brought into macroeconomics by Engle (1978), Watson and Engle (1983), Harvey and Todd (1983), Harvey (1985), and Watson (1986). These models allow one to consistently acknowledge the unobservability of potential output and the NAIRU, while incorporating economic content that is absent in many of the previously-used estimation methods.

Kuttner $(1991,1994)$ uses the STM/UC approach to derive estimates of potential output for the U.S. that are consistent with inflation being constant. Similarly, constant-inflation STM/UC measures of U.S. unemployment are provided by King et al. (1995), Staiger et al. (1996), and Gordon (1997). ${ }^{2}$ Kuttner (1991) also considers STM/UC estimation of potential output in the U.S. through an Okun's law equation, defined as a relationship between the

\footnotetext{
${ }^{1}$ The concepts of the NAIRU and potential output were introduced into macroeconomics in the 1960s. Some commonly cited references are Okun (1962), Phelps (1967), and Friedman (1968).

${ }^{2}$ Lindblad (1997) contains related estimates for Swedish unemployment.
} 
change in observable unemployment and unobservable cyclical output. As concerns Okun's law based U.S. NAIRU estimates, STM/UC models which link observable stationary output measures (for example, capacity utilisation rates or growth rates of real output variables) to unobservable cyclical unemployment measures have been analysed by Jaeger and Parkinson $(1990,1994){ }^{3}$

While the above-mentioned STM/UC models are preferable to earlier methods, they still have a main disadvantage, namely that of failing to propose a satisfactory model for describing the mutual dependency of output and unemployment. Rather than undertaking partial analyses of the NAIRU and potential output, this entails estimating a system of equations which explicitly incorporates the co-variation restrictions on cyclical output and cyclical unemployment suggested by theory. ${ }^{4}$ It is the purpose of this paper to propose such a system. Basically, the system has two key elements: (1) a Phillips curve which includes "supplyshock" variables and incorporates a constant-inflation restriction on the NAIRU; and (2) an Okun's law relationship which translates cyclical unemployment movements into cyclical output movements. Taken together, these elements give an STM/UC model which is consistent with the common definitions of the NAIRU and potential output, and thus can be used to derive economically interpretable measures of these key unobservable economic variables.

The remainder of the paper proceeds as follows. The next section gives a brief survey of methods, other than the STM/UC approach, that have been used to estimate potential output and the NAIRU. Section 3 specifies the STM/UC system for the NAIRU and potential real output applied in this paper. Section 4 shows how this system can be estimated using maximum likelihood and the Kalman filter. Section 5 presents the results obtained from subjecting Swedish quarterly data covering the time period 1970:1-1996:3 to the proposed decomposition. Extensions to the basic model are addressed in section 6. Section 7 concludes and provides a summary.

\footnotetext{
${ }^{3}$ The analyses of Jaeger and Parkinson also include Germany, Canada, and the U.K. Related exercises using Swedish and Danish data are contained in Assarsson and Jansson $(1995,1996)$.

${ }^{4}$ To our knowledge, the only presently existing model which incorporates such co-variation restrictions in an appropriate way is that of Clark (1989). However, in his model, no use of inflation data is made, and thus the interpretation of the extracted unobservables is unclear.
} 


\section{Methods for Estimating the NAIRU and Potential Output ${ }^{5}$}

Various methods have been suggested in the literature for estimating the NAIRU and potential output, ranging from more or less mechanically fitting of a trend in a time series of unemployment or GDP to using structural models of the labour market or the economy as a whole. In the following brief survey we focus mainly on the estimation of potential output although it should be noted that the methods described can in general, with appropriate adaptations, equally well be employed when estimating the NAIRU. ${ }^{6}$ The methods surveyed are the Hodrick-Prescott filter, the so-called multivariate filter of Laxton and Tetlow (1992), methods based on structural vector autoregressive models, and the production function approach. The STM or UC framework, which we adopt in the estimations, is described in sections 3 and 4.

\section{The Hodrick-Prescott Filter}

A common feature of the NAIRU and potential output is that they both reflect long-run developments, or trends, in data. Their estimation is therefore closely related to the problem in econometrics of transforming time series to induce stationarity. This means that different purely statistical methods can be applied to extract the trends in output and unemployment. One method of detrending time series which has been frequently used when estimating potential output is the Hodrick-Prescott (HP) filter, popularised by Hodrick and Prescott (1981, 1997). The HP filter emerged as a more flexible alternative to the, at the time, most common ways of detrending - fitting and subtracting a deterministic trend or taking first differences. In the HP filter potential output is defined as the solution to the following dynamic optimisation problem:

$$
\min \sum_{t=1}^{T}\left(y_{t}-y_{t}^{p}\right)^{2}+\lambda\left[\left(y_{t+1}^{p}-y_{t}^{p}\right)-\left(y_{t}^{p}-y_{t-1}^{p}\right)\right]^{2} \quad \text { w.r.t. } y_{t}^{p}
$$

\footnotetext{
${ }^{5}$ Readers already familiar with conventional methods for estimating potential output may skip this section and go directly to section 3 .

${ }^{6}$ For a survey of methods for estimating the NAIRU, see Staiger et al. (1996).
} 
where $y_{t}$ and $y_{t}^{p}$ are the logs of actual and potential output, respectively. Hence, the squared differences between actual and potential output are minimised subject to the constraint that squared variations in the growth of the trend component are penalised. The degree of penalty is determined by the smoothness parameter $\lambda$. A high value of $\lambda$ implies that fluctuations in the trend are heavily penalised and hence that the resulting series on potential output becomes smooth. A low value of the parameter, on the other hand, gives a series of potential output that follows actual output quite closely.

A shortcoming of the HP filter is that the degree of smoothness has to be determined $a$ priori on a judgmental basis, and therefore is exogenous with respect to the empirical analysis. Hence, the decomposition into trend and cycle makes no use of data on inflation and other cyclical variables. Furthermore, the HP filter tends to exaggerate the corrections at the end (as well as the beginning) of the sample. If, for example, the observation period ends with a marked downturn of output, the estimate of potential output may follow the actual downward path to an extent that in retrospect may turn out to be excessive. The explanation for this property is as follows. The HP optimisation problem contains a restriction on the fluctuations in potential output. Hence, if actual output drops at the end (or at the beginning) of the sample, the penalty of letting potential follow this downward path will be small because the filter does not take actual output's subsequent upturn (or previously higher values) into consideration. This property is unfortunate because it is usually the current value of potential output that is most pertinent to policy-makers. One way of dealing with this problem is to add projections of the actual GDP series. However, the accuracy of the current estimate of potential output will obviously critically depend on the quality of the forecasts.

The fact that $\lambda$ determines the variability of the trend component suggests that it should depend on the variances of the innovations to the cycle and trend components. Indeed, the specification in Hodrick and Prescott $(1981,1997)$ implies that $\lambda$ is equal to the ratio of the variances of the innovations in cycle and trend. However, King and Rebelo (1993) derive the 
condition under which the HP filter is an inverse optimal linear filter ${ }^{7}$ and find that the optimal smoothness parameter is a complicated function of the data generating processes of the trend and the cycle. Even with well-founded presumptions of the relative importance of shocks in trend and cycle, the choice of the smoothing parameter in the HP filter is therefore far from obvious. A HP filter where $\lambda$ is simply equal to the ratio of variances is optimal only if the change in the growth rate as well as the cyclical component are white noise processes. Since this data generating process implies that actual output is integrated of order two (that is, has a double unit root), it is unlikely to be valid in practice. Moreover, Harvey and Jaeger (1993) and Jaeger (1994) show that mechanical detrending based on the HP filter may extract spurious cyclical movements.

\section{The Multivariate Filter}

Laxton's and Tetlow's (1992) so-called multivariate filter (MV filter), which may be viewed as an extension of the HP filter, attempts to increase the precision in the estimate of potential output by introducing structural information into the trend-cycle decomposition. These authors suggested replacing (1) by:

$$
\min \sum_{t=1}^{T}\left(y_{t}-y_{t}^{p}\right)^{2}+\lambda_{p}\left[\left(y_{t+1}^{p}-y_{t}^{p}\right)-\left(y_{t}^{p}-y_{t-1}^{p}\right)\right]^{2}+\lambda_{\varepsilon} \varepsilon_{t}^{2}
$$

where $\varepsilon_{t}$ is the residual term in a structural relationship which involves potential output or the output gap (for example, a Phillips curve) and $\lambda_{\varepsilon}$ is the weight which is put on this term. Hence, the MV filter chooses the series of potential output that simultaneously minimises the squared differences between actual and potential output subject to a smoothness constraint (as in the HP filter) and a goodness-of-fit restriction from a structural relationship. The MV filter can therefore be seen as a semi-structural compromise between atheoretical filter techniques

\footnotetext{
${ }^{7}$ An optimal filter minimises the mean square error between the true cyclical component obtained from the data generating process and its estimate.
} 
and methods that are based on an assumed economic structure. It is of course also possible to introduce more than one structural relationship in (2). ${ }^{8}$

Although the MV filter is a considerable improvement compared to the HP filter, some problems still remain. One is that it might turn out to be technically difficult to simultaneously solve the HP-filter problem and compute the structural relationship that generates $\varepsilon_{t}$. Another problem is that the weights on the restrictions, $\lambda_{p}$ and $\lambda_{\varepsilon}$, somehow have to be determined. Laxton and Tetlow (1992) experiment with different combinations of a priori fixed weights, while Harvey and Jaeger (1993) and Côté and Hostland (1994) consider estimating the $\lambda_{i}$ s simultaneously with potential output. Côté and Hostland (1994) find that the estimated values of the $\lambda_{i}$ s depend on the exact specifications of the structural relationships. Furthermore, the MV filter does not directly address the end-of-sample problem of the HP filter. The introduction of structural terms is however likely to mitigate the problem to some extent. For example, if a recession at the end of the sample period is accompanied by a low inflation rate, then there is evidence that the change in actual output is cyclical. In this case, the inclusion of a Phillips-curve residual in (2) is likely to improve the accuracy of the identification of potential output and, equivalently, of the output gap. ${ }^{9}$

\section{Methods Based on Structural Vector Autoregressive Models}

A further step towards a structural estimation of potential output is to use vector-autoregressive (VAR) models that impose restrictions to identify structural components (so-called structural VAR (SVAR) models). To illustrate the approach, consider the following movingaverage representation of the underlying structural model (disregarding for simplicity deterministic variables):

$$
z_{t}=A(L) \varepsilon_{t},
$$

\footnotetext{
${ }^{8}$ Laxton and Tetlow (1992) use for example both a Phillips curve (that is, a relationship between the output gap and inflation) and an Okun's law relationship (that is, a relationship between the output gap and deviations of unemployment from the NAIRU).

${ }^{9}$ The Bank of Canada addresses the end-of-sample problem in the MV filter by adding a growth rate restriction which penalises deviations from the steady-state growth; see St-Amant and van Norden (1996).
} 
where $z_{t}$ is a stationary time-series vector in which the change in output, $\Delta y_{t}$, is one of the variables, $\varepsilon_{t}$ is a vector of uncorrelated zero-mean structural shocks with variances that are normalised so that $E\left(\varepsilon_{t} \varepsilon_{t}^{\prime}\right)=I$, and $A(L)=\sum_{i=0}^{\infty} A_{i} L^{i}$ is a matrix polynomial in the lag operator $L$ (that is, $L Z_{t} z_{t-i}$ ). For the purposes of estimating potential output, we would like to identify the part in each period's change in actual output that reflects a change in potential output. The shocks in the structural system (3) may be both permanent and transitory. In case potential output is assumed to correspond to the permanent component of output in system (3), then to obtain an estimate of potential output we need to identify these permanent and transitory shocks, and thus the structural model.

The first step in the identification of (3) is to estimate the unrestricted VAR:

$$
B(L) z_{t}=e_{t}
$$

where $e_{t}$ is a vector of reduced-form residuals with variance-covariance matrix $\Omega$. Because $z_{t}$ is stationary, system (4) can be inverted to yield the moving-average representation:

$$
z_{t}=C(L) e_{t}
$$

Representations (3) and (5) imply that the reduced-form residuals and the shocks of the structural model are related by the expression:

$$
e_{t}=A_{0} \varepsilon_{t}
$$

which implies that

$$
E\left(e_{t} e_{t}^{\prime}\right)=A_{0} E\left(\varepsilon_{t} \varepsilon_{t}^{\prime}\right) A_{0}^{\prime} \quad \text { or } \quad \Omega=A_{0} A_{0}^{\prime} \text {. }
$$

Expressions (3), (5), and (6) also imply that 


$$
A(L)=C(L) A_{0} .
$$

The equations in (6) and (7) suggest that the structural shocks $\varepsilon_{t}$ can be identified from the reduced-form residuals $e_{t}$ and their variance-covariance matrix $\Omega$, provided that there are sufficient identifying restrictions to evaluate the elements in $A_{0}$. While (7) provides some restrictions, some further restrictions are needed. If, for example, the VAR system contains three variables, $A_{0}$ as well as the estimated variance-covariance matrix $\Omega$ each contain nine elements. However, since $\Omega$ is symmetric, only six of its elements are distinct. This implies that three additional restrictions have to be imposed in order to identify all the elements of $A_{0}$.

When imposing the additional restrictions it is common to focus on long-run relationships. From (8) we note that the long-run effects of the structural shocks, $A(1)$, are related to the long-run effects of the estimated reduced-form shocks, $C(1)$, by the expression:

$$
A(1)=C(1) A_{0} \text {. }
$$

By imposing a sufficient number of restrictions on the elements of $A(1)$ (three in the example above) it is possible to identify all the elements of $A_{0}$. Having done this, the structural model (3) is exactly identified through (8).

The long-run restrictions may, as for example in DeSerres et al. (1995) and St-Amant and van Norden (1996), be imposed a priori on the basis of economic theory. Specifically, economic theory may motivate a division of the shocks of the structural model into shocks that have permanent effects and shocks that have transitory effects. It is, for example, common to identify shocks that have permanent effects on real output as supply shocks and shocks that have temporary effects as demand shocks (cf. Blanchard and Quah (1989), Shapiro and Watson (1988), and Galí (1992)). In case of a transitory shock, a zero element in the corresponding position in the $A(1)$ matrix is imposed. 
An alternative way of identifying the structural model would be to focus on the short run only. A common approach is to use a Choleski decomposition of $\Omega$ in which case $A_{0}$ is assumed to be lower triangular (Sims (1980)). This implies a recursive structural model and hence that the ordering of the equations in the system becomes important. However, long-run restrictions often seem to be easier to justify from a theoretical point of view and seem to be more useful when computing the variables we are primarily interested in here, potential output and the NAIRU.

Having identified the structural model in this way, the equation for the change in output can be written:

$$
\Delta y_{t}=\mu_{y}+A^{p}(L) \varepsilon_{t}^{p}+A^{c}(L) \varepsilon_{t}^{c},
$$

where $\mu_{y}$ is a (previously-omitted) constant, $\varepsilon_{t}^{p}$ is a vector of shocks with permanent effects on the level of output, and $\varepsilon_{t}^{c}$ is a vector of shocks with transitory (cyclical) effects on the level of output. Potential output can be defined as the permanent part of real output. Hence, the two first terms in (10) reflect a change in potential output:

$$
\Delta y_{t}^{p}=\mu_{y}+A^{p}(L) \varepsilon_{t}^{p} .
$$

If $A^{p}(L)=1$, then $y_{t}^{p}$ is a pure random walk with drift. For other $A^{p}(L), y_{t}^{p}$ contains a dynamic transitory part. The difference between (10) and (11) is the change in the cyclical part of output, or the change in the output gap. The level of potential output can be calculated by adding the effects of past permanent shocks to the projected linear trend in output, $\mu_{y} t$.

Long-run restrictions may alternatively (or additionally) be obtained from cointegrating relationships. Cointegrating restrictions are used by, for example, Blanchard and Quah (1989), King et al. (1991), and Cochrane (1994) to identify permanent shocks to real output, and by, for example, Dolado and López-Salido (1996) and Jacobson et al. (1996) to identify permanent shocks to unemployment. 
An advantage of basing the estimation of potential output on the SVAR methodology, compared to the previously-described methods, is that VAR models are better suited for forecasting. Furthermore, SVAR models do not suffer from the end-point problem that characterises methods based on mechanical filters. A weakness that the method shares with previous techniques is that it does not make explicit use of the definition of potential output - that inflation is constant when actual output equals potential.

\section{The Production Function Approach}

Since potential output is intended to reflect the supply side of the economy, an intuitive approach would be to specify a production function in line with Solow's (1956) neoclassical model where growth is a function of capital and labour, and the available technology. ${ }^{10}$ Potential output is obtained by inserting trend levels of the input components into the specified functional form. Assuming a Cobb-Douglas function, the production function can in logarithmic form be written:

$$
y_{t}^{p}=\alpha \bar{l}_{t}+(1-\alpha) \bar{k}_{t}+\bar{c}_{t} \text {, }
$$

where $y_{t}^{p}$ is potential output, $\bar{l}_{t}$ the trend in labour input, $\bar{k}_{t}$ the trend in capital input, $\bar{c}_{t}$ the trend in total factor productivity (representing the contribution from the available technology), and $\alpha$ the elasticity of potential output with respect to trend labour. ${ }^{11}$

An advantage of the production function approach is that changes in the estimated path of potential output can be attributed explicitly to the development of its input components. As a result, the output gap can be decomposed into its underlying components and it can, for example, be checked to what extent a negative output gap depends on an unusually low labour input (typically measured in working hours) or an unusually low total factor productivity. It is

\footnotetext{
${ }^{10}$ An application of the production function approach is given in Giorno et al. (1995).

${ }^{11}$ Because the amount of capital often is assumed to be fixed in the short run, it is common to use the actual capital stock, $k_{t}$, rather than its trend, $\bar{k}_{t}$, in (12).
} 
also possible to study the effects on potential output of different assumptions regarding the future development of the components.

An obvious weakness of the production function approach is that it does not address the problem of how to estimate the relevant trends for the components. For instance, an estimate of equilibrium unemployment or the NAIRU is an important component in the trend in labour input. The trend-estimation problem is therefore shifted from aggregate output to the different inputs in the production function. It should be noted that the previously-described methods can, with proper modifications, be used to estimate the trends that are required in the production function approach. Hence, while those methods can be seen as general estimation methods, the production function approach should perhaps rather be regarded as a transparent way of combining estimates of the input components of potential output.

\section{The Structural Time-Series/Unobserved Components System}

Like the SVAR model, the STM/UC approach is an attempt to introduce more economic structure into the estimation procedure. A general advantage of the STM/UC methodology is that the definitions of potential output and the NAIRU as the levels of output and unemployment where inflation is constant can be explicitly incorporated in the decomposition. Furthermore, a specific merit of the STM/UC model adopted in this paper is that it allows potential output and the NAIRU to be simultaneously estimated.

Before discussing the approach in detail it might be worthwhile to briefly give some intuition for it. To begin with, a model is specified which relates the unobservable variables potential output and the NAIRU to observable variables such as inflation, actual output, and actual unemployment. For example, in the model applied in this paper, inflation is related to potential output and the NAIRU through a Phillips curve and an Okun's law relationship. The specification of the model is presented in this section. In Section 4, which deals with estimation issues, it is shown how a recursive Kalman-filter algorithm can be applied to a socalled state-space representation of the model, in order to find a sequence of optimal predictions of the observable variables for a given set of coefficients and sequence of the 
unobservables. By comparing these predictions to the actual values of the observables, a specific series of forecast errors is obtained. These forecast errors are used in a maximumlikelihood routine to find the optimal set of parameters and the corresponding estimates of potential output and the NAIRU.

The first step in deriving economically interpretable measures of the NAIRU and potential output is to formulate explicit identifying equations for these unobservables. The following are the key identifying equations used in this paper:

$$
\pi_{t}=(1-\rho(1)) \pi^{*}+\rho(L) \pi_{t-1}+\eta(L)\left(u_{t}-u_{t}^{n}\right)+\omega(L) z_{t}+\varepsilon_{t}^{p c}
$$

and

$$
y_{t}-y_{t}^{p}=\phi(L)\left(u_{t}-u_{t}^{n}\right)+\varepsilon_{t}^{o l},
$$

where

$$
\begin{array}{ll}
\pi_{t} & =\text { price inflation, } \\
\pi^{*} & =\text { long-run inflation, } \\
u_{t} & =\text { the unemployment rate, } \\
y_{t} & =\text { (the log of) real output, } \\
z_{t} & \text { a vector of supply-shock proxies (normalised so that } z_{t}=0 \text { means that supply } \\
& \text { shocks are absent), } \\
u_{t}^{n} & \left.=\text { the NAIRU ( } E\left(u_{t}-u_{t}^{n}\right)=0\right), \\
y_{t}^{p} & \text { (the log of) potential output }\left(E\left(y_{t}-y_{t}^{p}\right)=0\right), \\
\varepsilon_{t}^{p c}, \varepsilon_{t}^{o l} & =\text { IID error terms }\left(E\left(\varepsilon_{t}^{p c}\right)=E\left(\varepsilon_{t}^{o l}\right)=0\right), \\
\rho(L), \eta(L), & =\text { polynomials in the lag operator } L .(\text { Here and in what follows all polynomials in } \\
\omega(L), \phi(L) & \text { the lag operator are one-sided and include contemporaneous parameters. That is, }
\end{array}
$$


Equation (13) is a modified version of Gordon's so-called triangle Phillips model (see, for example, Gordon (1997)). The label "triangle" is introduced to emphasise its dependence on a tripartite set of basic determinants: inertia $\left(\pi_{t-1}\right)$, demand $\left(u_{t}-u_{t}^{n}\right)$, and supply $\left(z_{t}\right)$. The equation has several features which deserve comments.

First, if inflation has a (conditional) unit root so that $\rho(1)=1$, the term which involves long-run inflation, $\pi^{*}$, on the right-hand side in (13) vanishes:

$$
\pi_{t}=\rho(L) \pi_{t-1}+\eta(L)\left(u_{t}-u_{t}^{n}\right)+\omega(L) z_{t}+\varepsilon_{t}^{p c}
$$

The fact that $\rho(1)=1$ ensures that this specification defines a meaningful NAIRU. This can easily be seen by noting that in equilibrium $\pi_{t}=\pi_{t-1}=\pi$ and $z_{t}=\varepsilon_{t}^{p c}=0$ for all $t$. Hence, from equation (15), $u_{t}=u_{t}^{n}$ for all $t$ if and only if $\rho_{0}+\rho_{1}+\ldots+\rho_{q}=1$, where $q$ is the order of the lag polynomial $\rho(L) .{ }^{12}$ Because $\rho_{0}+\rho_{1}+\ldots+\rho_{q}=1$ means that $\pi_{t}-\rho(L) \pi_{t-1}=\rho^{*}(L)(1-L) \pi_{t}$, equation (15) can with this restriction be rewritten so that the change in inflation is a function of $\Delta \pi_{t-i}, u_{t-j}-u_{t-j}^{n}$, and $z_{t-h} \quad(i=1,2, \ldots, q-1$, $j=0,1,2, \ldots, k, h=0,1,2, \ldots, l$, where $l$ is the order of $\omega(L))$. This formulation of the model more clearly shows the constant-inflation nature of the NAIRU measure.

Second, if inflation is a stochastically stationary variable, that is if $\rho(L)$ in (13) does not contain any unit roots, then in equilibrium with the unemployment rate equal to the NAIRU $\left(u_{t}-u_{t}^{n}=0\right)$ and with no shocks present $\left(z_{t}=\varepsilon_{t}^{p c}=0\right)$, inflation is not only constant but equals long-run inflation $\left(\pi_{t}=\pi_{t-1}=\pi^{*}\right)$. Such an approach may be justified by the fact that monetary policy in a large number of countries is directed towards explicit or implicit inflation targets and that the central bank, through its control of monetary aggregates, exerts a considerable influence on long-run inflation.

Third, in the original Phillips-curve specification the focus was on the co-variation between unemployment and wage inflation. Equation (13), however, involves a specification in terms of unemployment and price inflation. While the question of which measure of inflation

\footnotetext{
12 The precise statement actually is: $u_{t}=u_{t}^{n}$ for all $t \Rightarrow \rho_{0}+\rho_{1}+\ldots+\rho_{q}=1$ provided $\pi \neq 0$ and $\rho_{0}+\rho_{1}+\ldots+\rho_{q}=1 \Rightarrow u_{t}=u_{t}^{n}$ for all $t$ provided $\eta_{0}+\eta_{1}+\ldots+\eta_{k} \neq 0$, where $k$ is the order of $\eta(L)$.
} 
one should use essentially is an empirical one, it is emphasised that a specification in terms of price rather than wage inflation matches the formulations in Blanchard and Katz (1997) and Gordon (1997) in which nominal wages are implicitly solved out and only a reduced form is estimated..$^{13}$

Fourth, because of the inclusion of proxies for supply shocks $\left(z_{t}\right)$, the extracted NAIRU is the unemployment rate which is consistent with stable inflation in the absence of supply shocks. In general, ignoring the influence of supply changes gives rise to misspecification problems. Although, of course, it is difficult to identify which variables appropriately should appear in the $z_{t}$ vector, setting $z_{t}=0$ certainly is not preferable. The fact that the correlation between inflation and unemployment is positive rather than negative for some countries (especially in the 1970s) can probably to a large extent be attributed to supply shocks. The above-outlined specification explicitly addresses this problem by estimating the relationship between inflation and unemployment conditional on supply effects.

Fifth, it is common to interpret autoregressive lag polynomials in Phillips curves as components that capture expected inflation. Equation (15) may then be regarded as an expectations-augmented Phillips curve with expected inflation set equal to $\rho(L) \pi_{t-1}$. In equation (13), expected inflation would correspond to the two terms $(1-\rho(1)) \pi^{*}+\rho(L) \pi_{t-1}$. In the case of equation (15), the restriction $\rho_{0}+\rho_{1}+\ldots+\rho_{q}=1$ implicitly is a "no-equilibrium-expectation-error" assumption. To see this, note that for this equation the difference between actual and expected inflation in equilibrium simply is $(1-\rho(1)) \pi$. Hence, to ensure that there are no expectation errors in equilibrium with $\pi \neq 0$ we have to require that $\rho(1)=\rho_{0}+\rho_{1}+\ldots+\rho_{q}=1$. For (13), the difference between actual and expected inflation in equilibrium instead is $(1-\rho(1)) \pi-(1-\rho(1)) \pi^{*}$. Given that $\rho(1) \neq 1$, the requirement for no expectation errors in equilibrium with a non-zero inflation rate is hence that $\pi=\pi^{*}$. A critique against this way of representing expected inflation is that inflation may be autocorrelated for completely different reasons than expectation formation. For example, prices can adjust slowly because of wage and price contracts or because firms, due to for example imperfect information, do not react instantaneously to increases in their input costs. Thus, in

\footnotetext{
${ }^{13}$ Two recent papers which use wage rather than price inflation are Elmeskov (1993) and Ball (1996).
} 
our view, the role of the autoregressive components in equations (13) and (15) is to capture price inertia in general, whether related to expectations, nominal contracts, imperfect information, or anything else.

Equation (14), which translates cyclical unemployment fluctuations into cyclical output fluctuations, is a standard version of Okun's law. It is this equation that allows us to endogenously derive both estimates of the NAIRU and of potential output. As emphasised above, this is not possible with the previously-used formulations of this relationship. In his analysis of potential output, Kuttner (1991) used:

$$
\Delta u_{t}=\vartheta(L) \Delta u_{t-1}+\chi(L)\left(y_{t}-y_{t}^{p}\right)+e_{t}
$$

Similarly, the relationship exploited by Jaeger and Parkinson (1994) was:

$$
\Delta y_{t}=\vartheta^{*}(L) \Delta y_{t-1}+\chi^{*}(L)\left(u_{t}-u_{t}^{n}\right)+e_{t}^{*},
$$

where $\Delta y_{t}$ is the growth rate of some real output variable. Because, as pointed out above, Okun's law is a relationship between cyclical unemployment and cyclical output, these equations embody implicit trend-cycle assumptions. In particular, in the case of equation (16), $u_{t}-u_{t}^{n}=\Delta u_{t}$ and hence $u_{t}^{n}=u_{t-1}$. For the same reason, in the case of equation (17), $y_{t}^{p}=y_{t-1}$. While it may be argued that the validity of these implicit trend-cycle assumptions is an open question, it is important to properly understand what they imply and actually rely on. Indeed, since $\quad u_{t} \equiv u_{t}^{n}+\left(u_{t}-u_{t}^{n}\right) \quad$ and $\quad y_{t} \equiv y_{t}^{p}+\left(y_{t}-y_{t}^{p}\right), \quad \Delta u_{t} \equiv \Delta u_{t}^{n}+\Delta\left(u_{t}-u_{t}^{n}\right) \quad$ and $\Delta y_{t} \equiv \Delta y_{t}^{p}+\Delta\left(y_{t}-y_{t}^{p}\right)$. Thus, in general, $\Delta u_{t}$ and $\Delta y_{t}$ will depend on both the change in the trend and the change in the cycle, and the strategy of first differencing will therefore not produce a genuine cyclical component.

Having outlined and discussed the economic identifying equations of our STM/UC system, we now turn our attention to the structure of the system's atheoretical trend-cycle block. In essence, the specifications here follow the established standards for STM/UC decompositions. 
The relationships that are used to complete the system are the following:

$$
\begin{aligned}
& u_{t}^{n}=u_{t-1}^{n}+\varepsilon_{t}^{n}, \\
& y_{t}^{p}=\alpha+y_{t-1}^{p}+\varepsilon_{t}^{p},
\end{aligned}
$$

and

$$
u_{t}-u_{t}^{n}=\delta(L)\left(u_{t-1}-u_{t-1}^{n}\right)+\varepsilon_{t}^{c}
$$

where the innovations $\varepsilon_{t}^{n}, \varepsilon_{t}^{p}$, and $\varepsilon_{t}^{c}$ are assumed to be IID and $E\left(\varepsilon_{t}^{n}\right)=E\left(\varepsilon_{t}^{p}\right)=E\left(\varepsilon_{t}^{c}\right)=0$. All innovations of the system $\left(\varepsilon_{t}^{p c}, \varepsilon_{t}^{o l}, \varepsilon_{t}^{n}, \varepsilon_{t}^{p}\right.$, and $\left.\varepsilon_{t}^{c}\right)$ are assumed to be mutually uncorrelated and to have constant variances.

Equations (18) and (19) imply that both the NAIRU and potential output are assumed to be characterised by stochastic trends. More specifically, the NAIRU is assumed to follow a pure random walk whereas potential output is assumed to follow a random walk with drift. Hence, $u_{t}$ and $y_{t} \sim \mathrm{I}(1)$, or equivalently, $u_{t}$ and $y_{t}$ are unit-root processes. However, deterministic models are special cases of (18) and (19) and correspond to the restrictions $\operatorname{var}\left(\varepsilon_{t}^{n}\right)=0$ and $\operatorname{var}\left(\varepsilon_{t}^{p}\right)=0$. More specifically, if $\operatorname{var}\left(\varepsilon_{t}^{n}\right)=0, u_{t}^{n}=u^{n}$; and if $\operatorname{var}\left(\varepsilon_{t}^{p}\right)=0$, $y_{t}^{p}=\alpha t+y_{0}^{p} \cdot{ }^{14}$

Equation (20) specifies the assumed evolution of cyclical unemployment. The assumption of a purely autoregressive process for the unemployment cycle can be relaxed in favour of more general (and possibly more parsimonious) autoregressive moving-average specifications. In the present application, however, we typically find that a purely autoregressive process of low order fits the data well.

The empirical evidence from estimating the system is given in section 5. Before turning to that section, however, some issues related to estimation have to be addressed.

\footnotetext{
${ }^{14}$ It deserves here to be noted that if $u_{t}^{n}$ has a unit root, then the unemployment rate will not be restricted between its natural bounds 0 percent $\leq u_{t} \leq 100$ percent. A logistic transformation was applied to account for this problem. The results, which are available upon request, are unaffected by the transformation.
} 


\section{Estimation}

Models of the kind analysed in this paper can conveniently be estimated by maximum likelihood through the use of the Kalman filter. This requires writing the system in so-called state-space form. For expository convenience we assume that $\rho(L)=1$, that $\eta(L), \phi(L)$, and $\delta(L)$ are all zero-order polynomials, and that $\omega(L)=\alpha=0 .{ }^{15}$ This results in the following system:

$$
\begin{aligned}
& \left(\begin{array}{c}
y_{t} \\
u_{t} \\
\Delta \pi_{t}
\end{array}\right)=\left(\begin{array}{ccc}
1 & 0 & \phi_{0} \\
0 & 1 & 1 \\
0 & 0 & \eta_{0}
\end{array}\right)\left(\begin{array}{c}
y_{t}^{p} \\
u_{t}^{n} \\
u_{t}-u_{t}^{n}
\end{array}\right)+\left(\begin{array}{c}
\varepsilon_{t}^{o l} \\
0 \\
\varepsilon_{t}^{p c}
\end{array}\right) \text {, or } \\
& X_{t}=Z U_{t}+E_{t} \text { with } E\left(E_{t} E_{t}^{\prime}\right)=R,
\end{aligned}
$$

and

$$
\begin{aligned}
& \left(\begin{array}{c}
y_{t}^{p} \\
u_{t}^{n} \\
u_{t}-u_{t}^{n}
\end{array}\right)=\left(\begin{array}{ccc}
1 & 0 & 0 \\
0 & 1 & 0 \\
0 & 0 & \delta_{0}
\end{array}\right)\left(\begin{array}{c}
y_{t-1}^{p} \\
u_{t-1}^{n} \\
u_{t-1}-u_{t-1}^{n}
\end{array}\right)+\left(\begin{array}{c}
\varepsilon_{t}^{p} \\
\varepsilon_{t}^{n} \\
\varepsilon_{t}^{c}
\end{array}\right) \text {, or } \\
& U_{t}=T U_{t-1}+V_{t} \text { with } E\left(V_{t} V_{t}^{\prime}\right)=Q .
\end{aligned}
$$

System (21) is the so-called measurement system; system (22) is the so-called transition system. Once the STM/UC system has been put in state-space form, we can apply the Kalman filter to derive the log likelihood in prediction-error decomposition form. More precisely, using

$$
\begin{aligned}
& \hat{U}_{t \mid t-1}=T \hat{U}_{t-1 \mid t-1}, \\
& P_{t \mid t-1}=T P_{t-1 \mid t-1} T^{\prime}+Q,
\end{aligned}
$$

\footnotetext{
${ }^{15}$ The estimations presented in section 5 are based on more elaborated specifications, but the system used here is sufficiently general to illustrate the basic principles.
} 


$$
\hat{U}_{t \mid t}=\hat{U}_{t \mid t-1}+P_{t \mid t-1} Z^{\prime}\left(Z P_{t \mid t-1} Z^{\prime}+R\right)^{-1}\left(X_{t}-\hat{X}_{t \mid t-1}\right),
$$

and

$$
P_{t \mid t}=P_{t \mid t-1}-P_{t \mid t-1} Z^{\prime}\left(Z P_{t \mid t-1} Z^{\prime}+R\right)^{-1} Z P_{t \mid t-1}
$$

we can compute the recursive sequences $\hat{U}_{h \mid h-1}$ and $P_{h \mid h-1}, h=1,2, \ldots, N$ where $N$ is the total number of observations available. Here, $\hat{Y}_{t \mid s}=\mathrm{E}\left(\left.Y_{t}\right|_{s}\right)$, where $I_{s}$ denotes the information set available at time $s$ and $Y_{t}=U_{t}, X_{t}$. Furthermore, $P_{t \mid s}$ is the MSE associated with $\hat{U}_{t \mid s}$.

The equations embodied in expression (25) are the key equations of the Kalman filter. It is through these equations that we can update the estimate of $U_{t}$ from $\hat{U}_{t \mid t-1}$ to $\hat{U}_{t \mid t}$.

Next, given $\hat{U}_{t \mid t-1}$ system (21) provides us with an estimate of $X_{t}$ conditional on the information available at time $t-1$. The prediction error associated with this estimate is:

$$
v_{t}=X_{t}-\hat{X}_{t \mid t-1}=Z\left(U_{t}-\hat{U}_{t \mid t-1}\right)+E_{t}
$$

and

$$
E\left(v_{t} v_{t}^{\prime}\right) \equiv F_{t}=Z P_{t \mid t-1} Z^{\prime}+R
$$

It can be shown that the forecasting rules for $\hat{X}_{t \mid t-1}$ and $\hat{U}_{t \mid t-1}$ developed above are optimal (that is, have the smallest MSE) within the class of linear functions of the variables on which the forecast is based. However, if the initial values of $U_{t}$ and the disturbances $E_{t}$ and $V_{t}$ are multivariate Gaussian, then we can make the stronger claim that $\hat{X}_{t \mid t-1}$ and $\hat{U}_{t \mid t-1}$ are optimal amongst any functions of these variables. In addition, in this case, the distribution of $X_{t}$ conditional on the information available at time $t-1$ is Gaussian with log likelihood given by:

$$
\ln \left(L_{t}\right)=-\left(0.5 n \ln (2 \pi)+0.5 \ln \left(\left|F_{t}\right|\right)+0.5 v_{t}^{\prime} F_{t}^{-1} v_{t}\right)
$$


where $\left|F_{t}\right|$ denotes the determinant of $F_{t}$ and $n$ is the number of variables in $X_{t}$. The overall log likelihood, of course, is obtained by summing (29) over all usable observations. The maximum-likelihood estimates of the unknown parameters and the unobservable transition vector can be obtained by maximising the overall log likelihood numerically. ${ }^{16}$

\section{Empirical Results}

To recapitulate, our basic model consists of the following five equations:

$$
\begin{aligned}
& \pi_{t}=(1-\rho(1)) \pi^{*}+\rho(L) \pi_{t-1}+\eta(L)\left(u_{t}-u_{t}^{n}\right)+\omega(L) z_{t}+\varepsilon_{t}^{p c}, \\
& y_{t}-y_{t}^{p}=\phi(L)\left(u_{t}-u_{t}^{n}\right)+\varepsilon_{t}^{o l}, \\
& u_{t}^{n}=u_{t-1}^{n}+\varepsilon_{t}^{n}, \\
& y_{t}^{p}=\alpha+y_{t-1}^{p}+\varepsilon_{t}^{p}, \\
& u_{t}-u_{t}^{n}=\delta(L)\left(u_{t-1}-u_{t-1}^{n}\right)+\varepsilon_{t}^{c} .
\end{aligned}
$$

The empirical analysis is undertaken using Swedish quarterly data running from 1970:1 to 1996:3. Two different measures of inflation are examined: (1) the quarterly percentage change in the consumer price index (CPI) and (2) the quarterly percentage change in the implicit GDP deflator. The $z_{t}$ vector, which - as explained above - is intended to capture supply shocks, includes information on the real exchange rate, productivity, relative prices of imports and oil, and dummy variables reflecting changes in value-added taxes. ${ }^{17}$

\footnotetext{
${ }^{16}$ Of course, to make the maximisation procedure operational, starting values for all the unknown parameters and for $U_{t}$ and $P_{t}$ are needed. See, for example, Hamilton (1994), ch. 13, for a discussion of this issue. The overall log likelihood is maximised using a derivative-free SIMPLEX algorithm available in the program package RATS.

${ }^{17}$ For details concerning the variables used, see the appendix 1.
} 
It was shown in section 3 that when there is a unit root in inflation so that $\rho(1)=1$, the first term in (13) vanishes and the Phillips curve can be expressed in terms of $\Delta \pi_{t}$ rather than $\pi_{t}$. In the estimations below, we use equation (13) both with and without the restriction that $\rho(1)=1$; that is, we use both $\Delta \pi_{t}$ and $\pi_{t}$ as dependent variables. With two measures of inflation, this means that four different versions of the basic model are estimated. As concerns the orders of the lag polynomials, $\eta(L), \phi(L)$, and $\delta(L)$ are all throughout chosen to be first order. The appropriate orders of $\rho(L)$ and $\omega(L)$ turn out to vary depending on the precise specification of equation (13).

The maximum-likelihood estimates of the four versions of the basic model appear in table 1 . To save space, we only report results for key parameters. ${ }^{18}$ The corresponding (onesided) estimates of potential output, the output gap, the NAIRU, and cyclical unemployment are shown in figures 1 to $4 .^{19}$

\footnotetext{
${ }^{18}$ See appendix 2 for full details.

${ }^{19}$ The estimates are one-sided in the sense that they show the optimal predictions for period $t$ conditional on the information available in period $t$. Alternatively, two-sided (smoothed) estimates, which are conditioned on the information from the full sample, may be computed. Given the parameters of the model, one may argue that onesided estimates are preferable because they correspond to the information available to policy-makers in "real time".
} 
Table 1. Estimation results for the four different specifications of the Phillips curve.

\begin{tabular}{|ccccc||}
\hline Parameters & $\Delta \pi_{t}^{C P I}$ & $\Delta \pi_{t}^{\text {DEF }}$ & $\pi_{t}^{\text {CPI }}$ & $\pi_{t}^{\text {DEF }}$ \\
\hline \hline$\eta_{0}$ & $-0.49(0.11)$ & $-0.91(0.04)$ & $-0.32(0.31)$ & $-0.82(0.11)$ \\
$\eta_{1}$ & $0.43(0.17)$ & $0.88(0.05)$ & $0.18(0.59)$ & $0.50(0.35)$ \\
\hline $\begin{array}{c}\text { Sum of AR parame- } \\
\text { ters }\end{array}$ & -0.80 & -2.19 & 0.58 & 0.17 \\
\hline$\phi_{0}$ & $-5.24(0.00)$ & $-4.84(0.00)$ & $-5.02(0.00)$ & $-5.19(0.00)$ \\
$\phi_{1}$ & $3.47(0.00)$ & $3.01(0.00)$ & $3.23(0.00)$ & $3.36(0.00)$ \\
\hline$\alpha$ & $0.47(0.00)$ & $0.50(0.00)$ & $0.51(0.00)$ & $0.50(0.00)$ \\
\hline$\sigma_{p c}$ & $0.55(0.00)$ & $0.72(0.00)$ & $0.45(0.00)$ & $0.66(0.00)$ \\
$\sigma_{o l}$ & $0.80(0.00)$ & $0.79(0.00)$ & $0.78(0.00)$ & $0.79(0.00)$ \\
$\sigma_{p}$ & $4.03 \mathrm{e}-6(1.00)$ & $0.13(0.83)$ & $0.19(0.60)$ & $2.37 \mathrm{e}-6(1.00)$ \\
$\sigma_{c}$ & $0.11(0.00)$ & $0.12(0.00)$ & $0.12(0.00)$ & $0.12(0.00)$ \\
$\sigma_{n}$ & $0.19(0.00)$ & $0.18(0.00)$ & $0.18(0.00)$ & $0.19(0.00)$ \\
\hline \hline Log likelihood & -213.24 & -239.39 & -195.86 & -230.77 \\
No. of obs. & 105 & 103 & 106 & 103 \\
$Q_{y}(10)$ & 13.00 & 13.38 & 13.34 & 13.42 \\
$Q_{u}(10)$ & 10.50 & 11.11 & 10.58 & 10.81 \\
$Q_{\pi}(10)$ & 14.50 & 8.73 & 8.69 & 11.55 \\
\hline \hline
\end{tabular}

Notes: The parameters $\sigma_{j}(i=p c, o l, p, c, n)$ are standard deviations. $Q_{j}(10)(j=y, u, \pi)$ are Ljung-Box $Q$ tests against general serial correlation based on 10 autocorrelations. $P$ values are given within parentheses. 
Figure 1. Estimations with $\Delta \pi_{t}^{C P I}$ as the dependent variable.
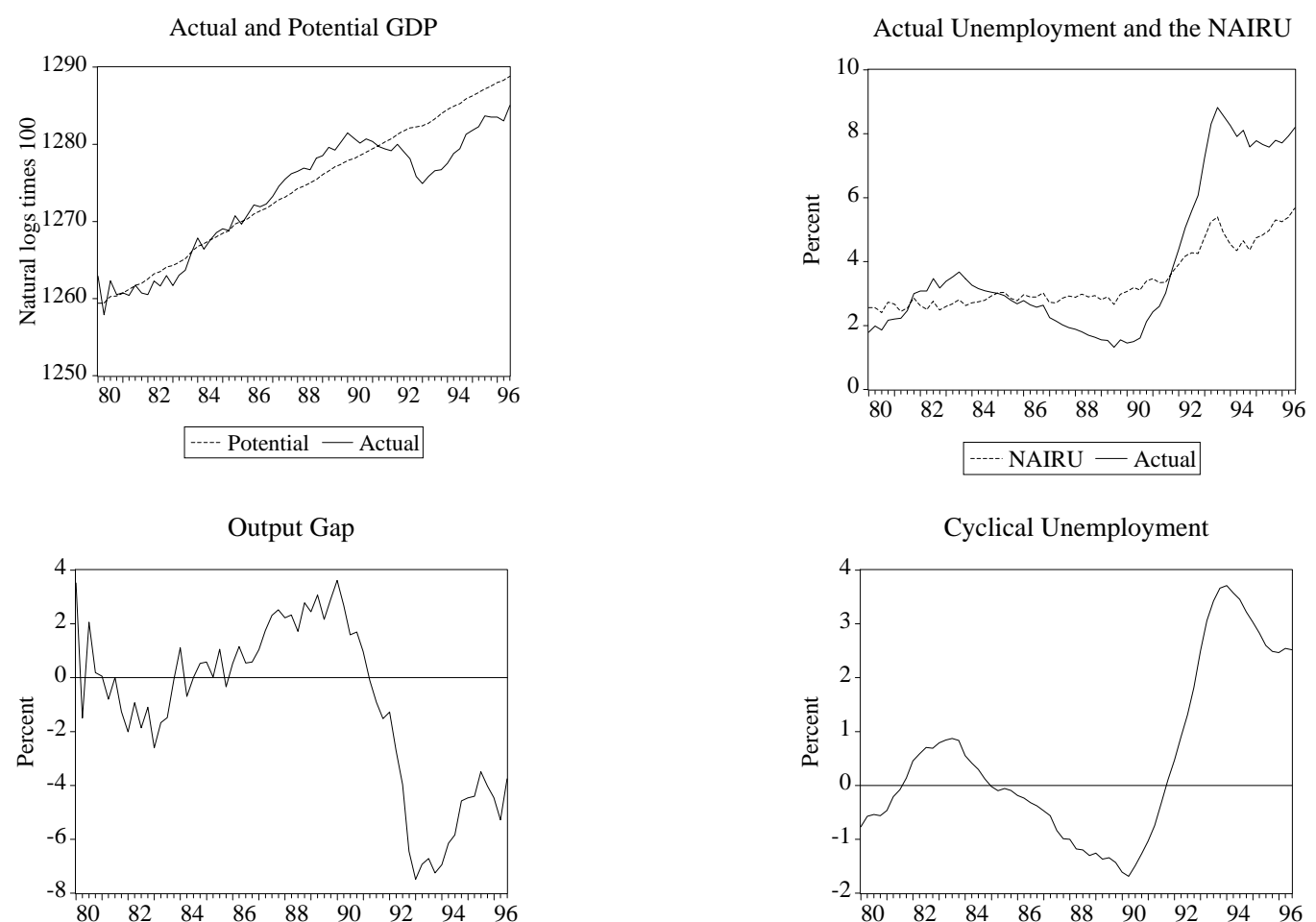

Figure 2. Estimations with $\Delta \pi_{t}^{D E F}$ as the dependent variable.
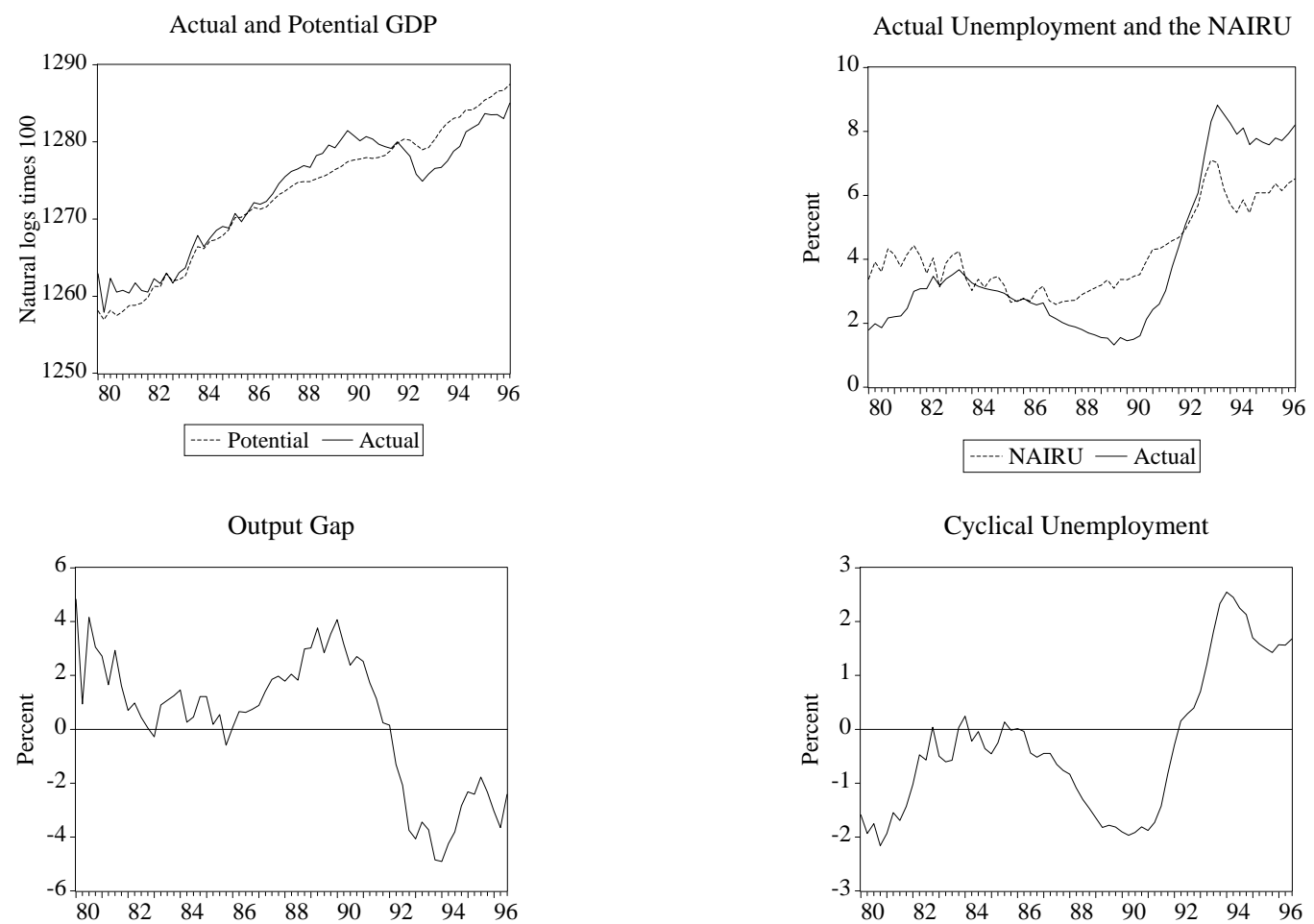
Figure 3. Estimations with $\pi_{t}^{C P I}$ as the dependent variable.

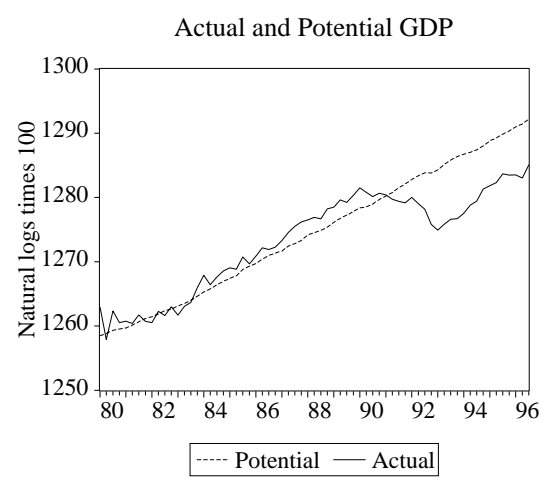

Actual Unemployment and the NAIRU
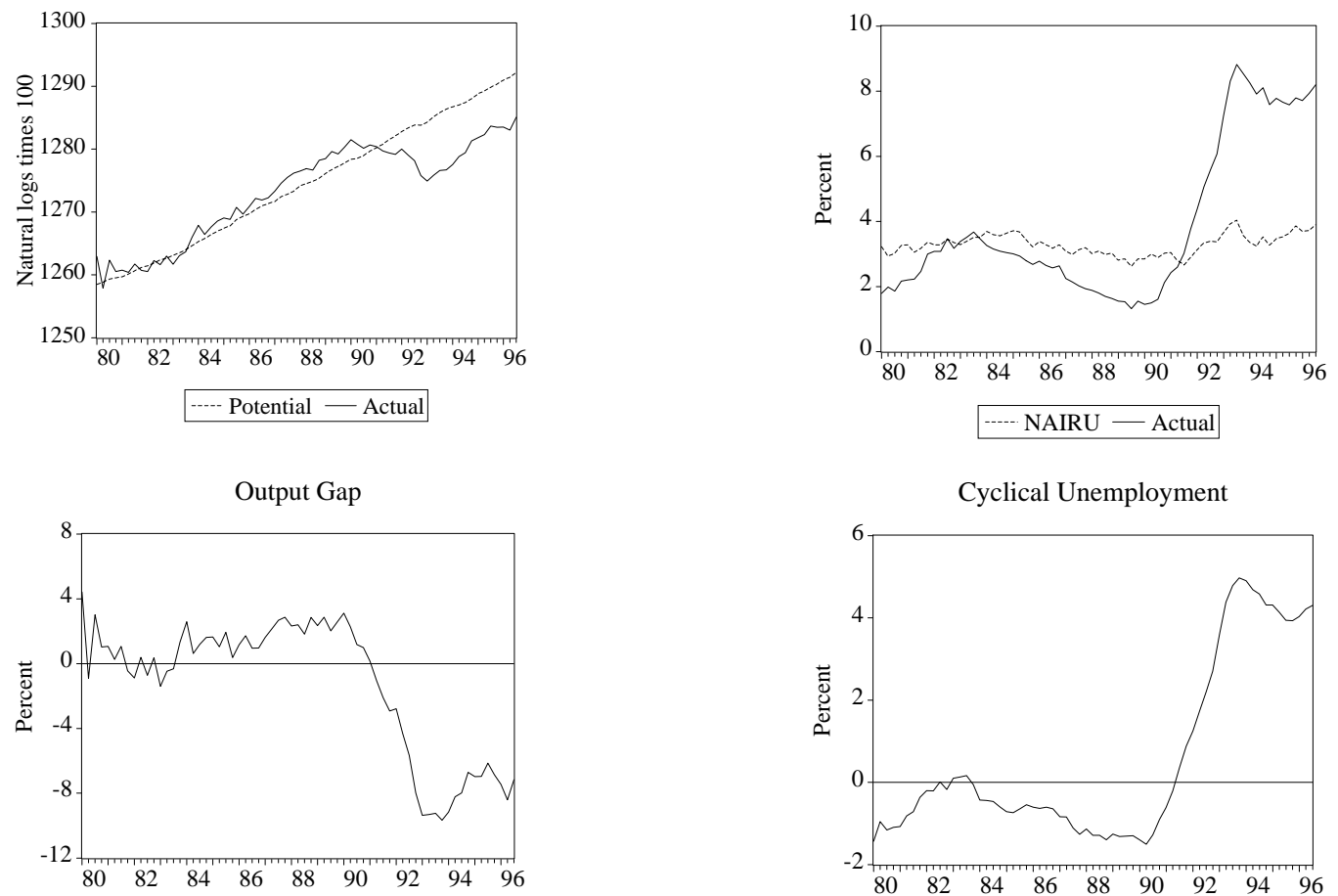

Figure 4. Estimations with $\pi_{t}^{D E F}$ as the dependent variable.
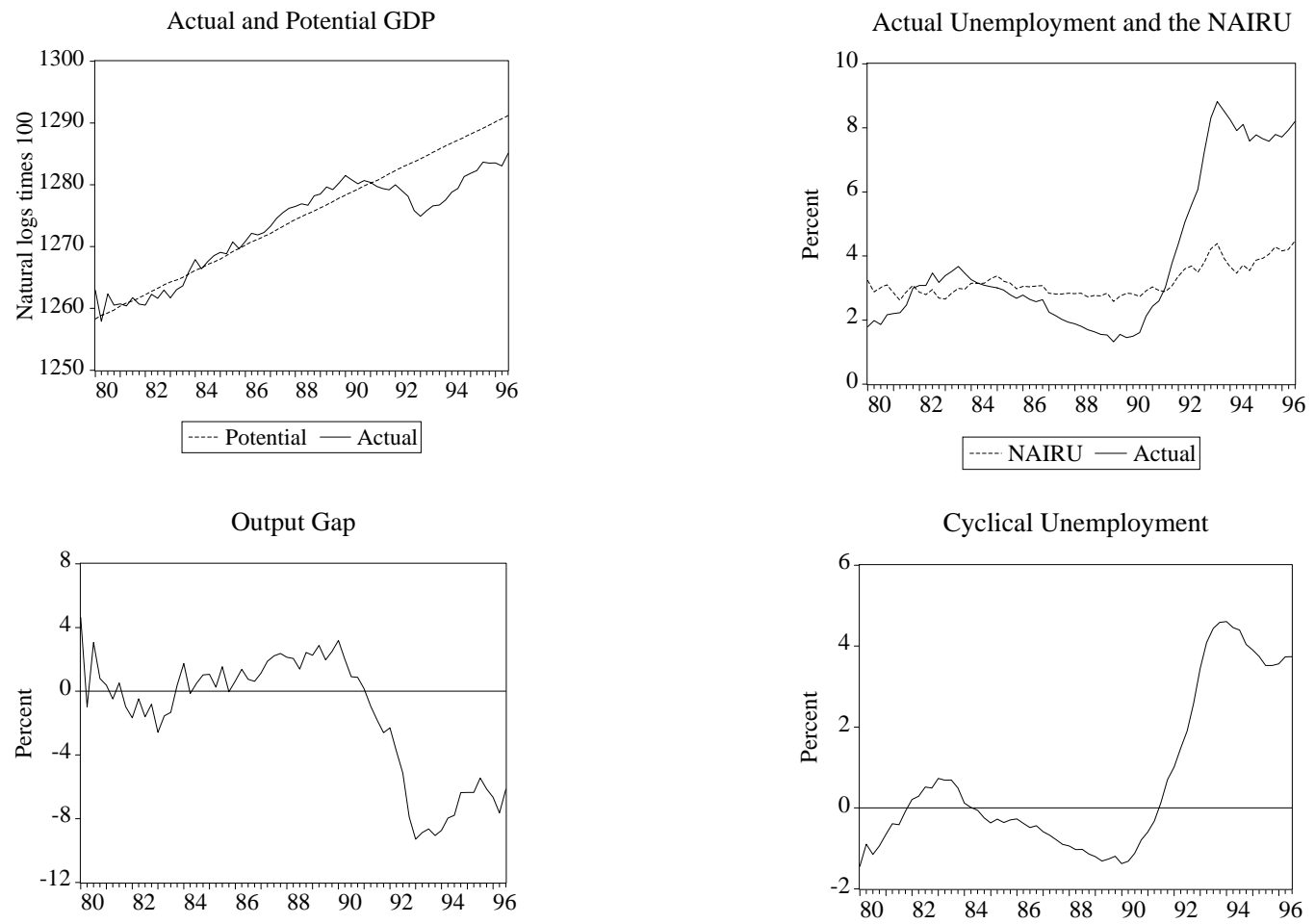
As can be seen from table 1, the estimates of the model are generally in accordance with economic theory. The sum of the coefficients on cyclical unemployment is negative in both the Phillips curve and in the Okun's law relationship, and, in most cases, the individual parameter estimates are statistically significant at the conventional levels of significance. Hence, generally, both the Phillips curve and the Okun's law relationship contribute to improving the statistical fit of the model. It deserves to be emphasised that the use of both contemporaneous and lagged cyclical unemployment in the Phillips curve implies that the unemployment gap may affect inflation both through level and change effects. This can be seen by noting that the contribution of cyclical unemployment in the Phillips curve, $\eta_{0}\left(u_{t}-u_{t}^{n}\right)+\eta_{1}\left(u_{t-1}-u_{t-1}^{n}\right)$, may equivalently be written as $\left(\eta_{0}+\eta_{1}\right)\left(u_{t}-u_{t}^{n}\right)-\eta_{1} \Delta\left(u_{t}-u_{t}^{n}\right)$ or $\left(\eta_{0}+\eta_{1}\right)\left(u_{t-1}-u_{t-1}^{n}\right)+\eta_{0} \Delta\left(u_{t}-u_{t}^{n}\right)$. Hence, level effects are captured by the sum of the coefficients while change effects are captured by the individual coefficients themselves. ${ }^{20}$ The results in table 1 suggest that change effects are quite substantial compared to level effects.

The estimates of the trend growth rate of potential output, $\alpha$, indicate an annual growth rate of around 2 percent. The generally small value of $\sigma_{p}$ suggests that the trend process of potential output is smooth, resembling a deterministic linear trend. An alternative specification of equation (19) is considered below.

Figures 1 to 4 indicate that the results for the four specifications share some common features. For example, they all give a negative current output gap and a positive current cyclical unemployment rate. However, there are also substantial differences. One is that the current deviations of actual output and actual unemployment from potential output and the NAIRU, respectively, are considerably larger for the specifications where the level of inflation is used as the dependent variable. To understand this result, it is important to remember that when the level of inflation is used, $\pi_{t}=\pi_{t-1}=\pi^{*}$ in equilibrium where $u_{t}=u_{t}^{n}$ and $z_{t}=\varepsilon_{t}^{p c}=0$. Because $\pi^{*}$ relates directly to average inflation which was very high during the 1970s and

\footnotetext{
${ }^{20}$ It can be noted that a specification which expresses the Phillips curve in terms of $\Delta \pi_{t}$ allows for increasing inflation even when $u_{t}-u_{t}^{n}<0$ if the reduction in $u_{t}-u_{t}^{n}$ is sufficiently large. When $\pi_{t}$ is the dependent variable, inflation may in an analogous way exceed $\pi^{*}$ even when $u_{t}-u_{t}^{n}<0$. When this occurs it is common to say that a "speed limit" effect is in operation. In a specification with two lags of cyclical unemployment, level effects would be captured by $\eta_{0}+\eta_{1}+\eta_{2}$ while change effects would be captured by $\eta_{0}, \eta_{2}, \eta_{0}+\eta_{1}$, and $\eta_{1}+\eta_{2}$.
} 
1980s, using an estimation period which includes these inflationary decades will, ceteris paribus, imply a higher point estimate of $\pi^{*}$. In other words, the rate of inflation consistent with $u_{t}=u_{t}^{n}$ will - in this case - be considerably higher than the current Swedish inflation target of 2 percent. This should be taken into consideration when interpreting cyclical unemployment and the output gap for this specification.

The same problem can be illustrated in another way. It was noted in section 3 that in the specification with the level of inflation, the two terms $(1-\rho(1)) \pi^{*}+\rho(L) \pi_{t-1}$ could be interpreted as expected inflation (disregarding other causes of price inertia). This would imply that expected inflation is generated by a mean-reverting, stationary, process. It might however be argued that this is not an appropriate assumption when inflation is characterised by substantial shifts over time. For example, a substantial downward shift in inflation took place in Sweden in the beginning of the 1990s, to a major extent as a result of a less accommodating economic policy than during previous decades. Since then, inflation has remained subdued. An explicit inflation target was introduced in the beginning of 1993 and the political emphasis of the benefits of price stability is today considerably stronger than during the 1970s and 1980s. This suggests that it is likely that $\pi^{*}$ in the future will be lower than during previous decades. In such a case, the process $(1-\rho(1)) \pi^{*}+\rho(L) \pi_{t-1}$ may not be a sufficiently flexible representation of expectations, and a specification which allows $\pi^{*}$ to shift over time may be needed.

\section{Extensions to the Basic Model}

In order to investigate how sensitive the results are to further changes in the specification, we extend the basic model in three different ways. To keep the number of estimations at a minimum, the analysis is throughout this section undertaken in terms of CPI only.

The first extension is motivated by the above-discussed shift to a lower inflation rate in the beginning of the 1990s. To test empirically whether a shift from a high-inflation to a lowinflation regime actually has taken place, we introduce a dummy variable so that $\pi^{*}$ becomes time dependent. In the model which uses the level of inflation, the dummy variable is set to 1 
from the first quarter of 1993 and onwards. ${ }^{21}$ Since a permanent shift in the level of a variable implies a one-period shift in the change of that variable, the dummy variable in the model with the change of inflation is set to 1 in the first quarter of 1993 and elsewhere 0 .

The empirical results are somewhat mixed. For the specification with $\Delta \pi_{t}^{C P I}$ as the dependent variable, the (LR) test statistic for exclusion of the shift dummy has the $p$ value 0.20 ; that is, the existence of a shift in the inflation process cannot be verified empirically at the conventional levels of significance. The specification with $\pi_{t}^{C P I}$, however, is a borderline case with a $p$ value of $0.052 .{ }^{22}$

These results reflect a general dilemma associated with the estimation of inflation processes that recently have experienced a change to a new monetary regime. From a theoretical point of view one may argue that since the central bank has a decisive influence over long-run inflation (that is, inflation is a monetary phenomenon in the long run), it seems reasonable to assume that long-run inflation should not be significantly different from the bank's explicit or implicit inflation target. However, if the change to a low-inflation regime has taken place recently - as it has in the case of Sweden - econometric methods may have difficulties in verifying the shift empirically due to an insufficient number of observations under the new regime.

The second extension of the basic model is to allow for a time-varying trend growth rate of potential output; that is, we relax the assumption of a constant drift term, $\alpha$, in equation (19). Kuttner (1991, 1994) uses a constant drift term when estimating potential output in the U.S. The results in Clark (1989) suggest that this may be a reasonable assumption for the U.S. and some other countries but that a time-varying drift term may well be motivated for countries that have experienced pronounced changes in their trend growth rates. A time-varying drift term is also used by Gerlach and Smets (1997) when estimating potential output for the

\footnotetext{
${ }^{21}$ The choice of shift date is motivated by the introduction of an explicit inflation target of 2 percent \pm 1 percentage point in the beginning of 1993. The choice of shift date is however not obvious. Because actual inflation fell dramatically already in 1992, one may argue that the regime shift occurred before the introduction of the explicit inflation target. On the other hand, because there is survey evidence that inflation expectations remained above 3 percent until 1995, one may also argue that the shift occurred after the introduction of the inflation target.

${ }^{22}$ For the specifications with $\Delta \pi_{t}^{D E F}$ and $\pi_{t}^{D E F}$, the $p$ values are 0.27 and 0.83 , respectively.
} 
G7 countries. Following Clark (1989), we assume that the drift follows a random walk so that $\alpha_{t}=\alpha_{t-1}+\varepsilon_{t}^{\alpha} .^{23}$

Irrespective of whether $\Delta \pi_{t}^{C P I}$ or $\pi_{t}^{C P I}$ is used as the dependent variable in the Phillips curve, it turns out that the hypothesis that the variance of $\varepsilon_{t}^{\alpha}$ is equal to 0 cannot be rejected. Hence, the assumption of a constant drift term does not seem to significantly violate Swedish data.

The third extension is to allow for some cross-equation correlation between the error terms in the system. In the basic model, the variance-covariance matrix is given by:

$\Omega=\left(\begin{array}{ccccc}\sigma_{p c}^{2} & 0 & 0 & 0 & 0 \\ 0 & \sigma_{o l}^{2} & 0 & 0 & 0 \\ 0 & 0 & \sigma_{n}^{2} & 0 & 0 \\ 0 & 0 & 0 & \sigma_{p}^{2} & 0 \\ 0 & 0 & 0 & 0 & \sigma_{c}^{2}\end{array}\right)$

That is, all shocks are assumed to be mutually uncorrelated and to have constant variances. The system given by equations (13) (or (15)), (14), and (18)-(20) is econometrically overidentified. This means that we can relax the assumption of a diagonal variance-covariance matrix, and allow for a non-diagonal $\Omega$ without making the system under-identified.

There are several reasons why some non-zero correlation may occur between the error terms. For example, hysteresis effects in the labour market may imply that there is a correlation between NAIRU shocks and shocks to cyclical unemployment $\left(\operatorname{cov}\left(\varepsilon_{t}^{n}, \varepsilon_{t}^{c}\right) \neq 0\right)$. (Cf. Jaeger and Parkinson (1990, 1994).) Also, the literature on sectoral shifts suggests sources of non-zero correlation between shocks to $u_{t}^{n}$ and $y_{t}^{p}\left(\operatorname{cov}\left(\varepsilon_{t}^{n}, \varepsilon_{t}^{p}\right) \neq 0\right)$. (Cf. Kuttner (1991).) The results obtained when estimating models which allow for non-diagonal $\Omega \mathrm{s}$, however, suggest that the assumption of orthogonality between shocks cannot be rejected. (The lowest $p$ value obtained when allowing $\operatorname{cov}\left(\varepsilon_{t}^{n}, \varepsilon_{t}^{c}\right) \neq 0$ or $\operatorname{cov}\left(\varepsilon_{t}^{n}, \varepsilon_{t}^{p}\right) \neq 0$ under the alternative, is 0.57.) The basic model with a diagonal $\Omega$ does therefore not seem to be overly restrictive.

\footnotetext{
${ }^{23} \mathrm{~A}$ critique against this approach is that it implies that output is integrated of order two (that is, that it has a double unit root). This assumption is, of course, questionable.
} 


\section{Summary and Conclusions}

Empirical analyses often treat the concepts of potential output and the NAIRU separately. At one level this dichotomy appears natural, with different theories providing insights into specific aspects in different markets. But on another level this distinction is artificial: theories explaining only potential output or only the NAIRU cannot provide adequate insights if there are important interactions between the two.

In this paper we take this challenge seriously and propose a new system-based strategy for estimating potential output and the NAIRU. The system has two key elements: (1) a Phillips-type equation which, under a specified set of conditions, defines the NAIRU as the longrun unemployment rate consistent with steady inflation; and (2) a standard version of Okun's law which states that deviations of unemployment from the NAIRU induce deviations of the level of output from its potential level. Taken together, these key elements give an empirical system which is consistent with the common definitions of potential output and the NAIRU, and thus can be used to derive economically interpretable estimates of these key unobservable macro variables.

The performance of the procedure is investigated using Swedish quarterly data covering the time period 1970:1-1996:3. Our empirical conclusions are as follows: (1) Estimating potential output and the NAIRU subject to co-variation restrictions on cyclical output and cyclical unemployment (that is, subject to a standard version of Okun's law) considerably improves the statistical fit of the model; (2) Incorporating information on inflation through a well-specified Phillips-type equation further helps in obtaining more precise estimates of potential output and the NAIRU; (3) While different specifications yield estimates that are qualitatively similar and generally in accordance with economic theory, the point estimates of the current output gap and NAIRU differ considerably across different specifications; (4) The trend process of potential (and actual) output in Sweden is smooth, resembling a deterministic linear trend. This result appears robust with respect to reasonable alterations of the specified process for potential output; (5) The recent shift from a high to a low inflation in Sweden 
gives rise to econometrical complications and necessitates a careful interpretation of the current estimates of the output gap and the NAIRU. The main problem is that, even though several compelling arguments indicate that a permanent shift in the inflation regime actually has taken place, an insufficient number of observations under the new regime makes it difficult to verify this empirically. 


\section{Appendix 1}

\section{Data Description}

The quarterly data set runs from 1970:1 to $1996: 3$. The precise estimation periods used vary according to the number of lags and unobserved components in the specifications. All series are seasonally adjusted except for the real effective foreign exchange rate, the oil price, and the index for the price of imports. The method used for seasonal adjustment is the additive version of X11. Price inflation is defined as $100 \Delta \ln \left(P_{t}\right)$, where $P_{t}$ is the consumer price index or the implicit GDP deflator (quarterly averages, 1991=100). Unemployment is measured in percent of the labour force while output is expressed as $100 \ln \left(G D P_{t}\right)$, where $G D P_{t}$ is real GDP in fixed 1991 prices. The relative prices of oil and imports are defined as 100(ln $\left.\left(O I L_{t}\right)-\ln \left(P_{t}\right)\right)$ and $100\left(\ln \left(I M P_{t}\right)-\ln \left(P_{t}\right)\right)$, where $O I L_{t}$ is the price of oil and $I M P_{t}$ is the implicit import deflator. The oil price is converted from USD to SEK per barrel (brent). Productivity is defined as $100\left(\ln \left(G D P_{t}\right)-\ln \left(H_{t}\right)\right)$, where $H_{t}$ is hours worked. The real exchange rate is defined as $100 \ln \left(R E X_{t}\right)$, where $R E X_{t}$ is the geometric sum (IMF's TCW weights) of the CPI-based real exchange rates of Sweden's 20 most important trading partners. The dates of the changes in value-added taxes used to construct the dummy variables are 70:1, 70:4, 71:1, 74:4, 77:2, 79:3, 80:4, 81:4, 83:1, 90:1, 90:3, 91:1, 92:1, 93:1, 93:3, 94:1, 95:1, and 96:1. Except for the dummy variables in the specifications where inflation is expressed in levels, all variables in the supply-variable vector $z_{t}$ are expressed in first differences. The source of all series except the oil price and the real exchange rate is Statistics Sweden. The oil price in USD is taken from the EcoWin database and nominal exchange rates from Sveriges Riksbank. 


\section{Appendix 2}

Table A1. Full estimation results for the four different specifications of the Phillips curve.

\begin{tabular}{|c|c|c|c|c|}
\hline Parameters & $\Delta \pi_{t}^{C P I}$ & $\Delta \pi_{t}^{D E F}$ & $\pi_{t}^{C P I}$ & $\pi_{t}^{D E F}$ \\
\hline$\eta_{0}$ & $-0.49(0.11)$ & $-0.91(0.04)$ & $-0.32(0.31)$ & $-0.82(0.11)$ \\
\hline$\eta_{1}$ & $0.43(0.17)$ & $0.88(0.05)$ & $0.18(0.59)$ & $0.50(0.35)$ \\
\hline $\mathrm{AR}(1)$ & $-0.38(0.00)$ & $-0.92(0.00)$ & $0.22(0.00)$ & $-0.20(0.04)$ \\
\hline $\mathrm{AR}(2)$ & $-0.42(0.00)$ & $-0.79(0.00)$ & - & - \\
\hline $\operatorname{AR}(3)$ & - & $-0.49(0.00)$ & $0.36(0.00)$ & - \\
\hline $\operatorname{AR}(4)$ & - & - & - & $0.37(0.00)$ \\
\hline REXCH(-1) & $0.07(0.01)$ & - & $0.05(0.05)$ & - \\
\hline REXCH(-2) & - & - & - & - \\
\hline REXCH(-8) & $0.10(0.00)$ & - & $0.09(0.00)$ & - \\
\hline $\mathrm{MA}(\mathrm{REXCH})(0)$ & - & $0.31(0.03)$ & - & $0.42(0.00)$ \\
\hline MA(REXCH)(-1) & - & $-0.24(0.08)$ & - & $-0.22(0.10)$ \\
\hline $\operatorname{PROD}(0)$ & - & $-0.11(0.14)$ & $-0.10(0.02)$ & $-0.13(0.05)$ \\
\hline PROD(-1) & $-0.06(0.19)$ & $-0.13(0.07)$ & $-0.05(0.28)$ & $-0.12(0.06)$ \\
\hline PROD(-3) & - & - & - & $0.06(0.26)$ \\
\hline PROD(-4) & - & $0.11(0.13)$ & - & - \\
\hline PROD(-5) & - & $0.12(0.11)$ & - & $0.07(0.26)$ \\
\hline PROD(-8) & $0.12(0.03)$ & - & $0.14(0.00)$ & - \\
\hline RELIMP(0) & $-0.05(0.09)$ & - & $-0.03(0.30)$ & - \\
\hline RELIMP(-1) & - & - & $0.03(0.21)$ & - \\
\hline RELIMP(-2) & $-0.09(0.01)$ & - & $-0.06(0.02)$ & - \\
\hline RELIMP(-3) & $0.05(0.03)$ & - & $0.02(0.36)$ & - \\
\hline RELIMP(-7) & - & - & $0.03(0.06)$ & - \\
\hline RELIMP(-8) & $-0.12(0.00)$ & - & $-0.09(0.01)$ & - \\
\hline MA(RELIMP)(0) & - & $-0.70(0.00)$ & - & $-0.96(0.00)$ \\
\hline MA(RELIMP)(-1) & - & $1.19(0.00)$ & - & $1.17(0.00)$ \\
\hline MA(RELIMP)(-2) & - & $-0.47(0.00)$ & - & $-0.27(0.03)$ \\
\hline RELOIL(0) & $0.02(0.00)$ & - & $0.01(0.00)$ & - \\
\hline RELOIL(-2) & $0.01(0.01)$ & - & $0.01(0.03)$ & - \\
\hline RELOIL(-3) & - & - & $0.01(0.01)$ & - \\
\hline RELOIL(-8) & $0.01(0.02)$ & - & $0.01(0.03)$ & - \\
\hline MA(RELOIL)(0) & - & $0.02(0.38)$ & - & $0.08(0.00)$ \\
\hline MA(RELOIL)(-1) & - & $-0.05(0.09)$ & - & $-0.08(0.00)$ \\
\hline MA(RELOIL)(-2) & - & $0.04(0.05)$ & - & $0.04(0.03)$ \\
\hline
\end{tabular}


Table A1. (continued)

\begin{tabular}{|c|c|c|c|c|}
\hline Parameters & $\Delta \pi_{t}^{C P I}$ & $\Delta \pi_{t}^{D E F}$ & $\pi_{t}^{C P I}$ & $\pi_{t}^{D E F}$ \\
\hline D74 & "1.10(0.03) & 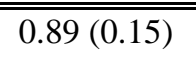 & " - & - \\
\hline D77 & $1.13(0.01)$ & - & $2.07(0.00)$ & $0.83(0.24)$ \\
\hline D80 & - & $1.67(0.00)$ & - & $2.46(0.00)$ \\
\hline D81 & $-1.04(0.02)$ & - & $-1.33(0.01)$ & $-0.62(0.42)$ \\
\hline D83 & - & $-0.72(0.18)$ & - & - \\
\hline D90 & $0.82(0.05)$ & $1.68(0.01)$ & $1.91(0.00)$ & - \\
\hline D91 & $0.87(0.05)$ & - & $1.57(0.00)$ & - \\
\hline D92 & $-1.45(0.00)$ & $-1.44(0.01)$ & $-1.76(0.00)$ & $-2.07(0.01)$ \\
\hline D93 & $1.60(0.00)$ & $0.93(0.10)$ & $2.01(0.00)$ & $1.26(0.12)$ \\
\hline D95 & - & - & - & $1.59(0.03)$ \\
\hline$\phi_{0}$ & $-5.24(-0.00)$ & $-4.84(0.00)$ & $-5.02(0.00)$ & $-5.19(0.00)$ \\
\hline$\phi_{1}$ & $3.47(0.00)$ & $3.01(0.00)$ & $3.23(0.00)$ & $3.36(0.00)$ \\
\hline$\alpha$ & $0.47(0.00)$ & $0.50(0.00)$ & $0.51(0.00)$ & $0.50(0.00)$ \\
\hline$\delta$ & $1.86(0.00)$ & $1.85(0.00)$ & $1.86(0.00)$ & $1.86(0.00)$ \\
\hline$\delta_{2}$ & $-0.88(0.00)$ & $-0.85(0.00)$ & $-0.87(0.00)$ & $-0.87(0.00)$ \\
\hline$\sigma_{p c}$ & $0.55(0.00)$ & $0.72(0.00)$ & $0.45(0.00)$ & $0.66(0.00)$ \\
\hline$\sigma_{o l}$ & $0.80(0.00)$ & $0.79(0.00)$ & $0.78(0.00)$ & $0.79(0.00)$ \\
\hline$\sigma_{p}$ & 4.03e-6 (1.00) & $0.13(0.83)$ & $0.19(0.60)$ & $2.37 e-6(1.00)$ \\
\hline$\sigma_{c}$ & $0.11(0.00)$ & $0.12(0.00)$ & $0.12(0.00)$ & $0.12(0.00)$ \\
\hline$\sigma_{n}$ & $0.19(0.00)$ & $0.18(0.00)$ & $0.18(0.00)$ & $0.19(0.00)$ \\
\hline Log likelihood & -213.24 & -239.39 & -195.86 & -230.77 \\
\hline No. of obs. & 105 & 103 & 106 & 103 \\
\hline$Q_{y}(10)$ & 13.00 & 13.38 & 13.34 & 13.42 \\
\hline$Q_{u}(10)$ & 10.50 & 11.11 & 10.58 & 10.81 \\
\hline$Q_{\pi}(10)$ & 14.50 & 8.73 & 8.69 & 11.55 \\
\hline
\end{tabular}

Notes: $\operatorname{AR}(p)$ denotes an autoregressive parameter at lag $p \cdot \operatorname{REXCH}(q)$ denotes a parameter on the $q$ th lag of the $\log$ difference of the real exchange rate (multiplied by 100). $\operatorname{PROD}(q)$ denotes a parameter on the $q$ th lag of the log difference of productivity (multiplied by 100). RELIMP $(q)$ denotes a parameter on the $q$ th lag of the log difference of the relative price of imports (multiplied by 100). RELOIL(q) denotes a parameter on the $q$ th lag of the log difference of the relative price of oil (multiplied by 100). D74-D95 are dummy variables capturing the effects of changes in value-added taxes (for further details see appendix 1 and the discussion in section 6). $\operatorname{MA}(x)(q)$ denotes a parameter on the $q$ th lag of a fourth order moving average of the variable $x . P$ values are given within parentheses. For further details see table 1 in section 5 . It should be noted that whilst the theoretical discussions treat the models based on $\Delta \pi_{t}^{i}(i=C P I, D E F)$ as special cases of the models based on $\pi_{t}^{i}$, in the econometrical applications these models are determined empirically from the data, independently of each other. 


\section{References}

Assarsson, B. and P. Jansson (1995), "Some further evidence on hysteresis in unemployment rates: the cases of Denmark and Sweden", Working Paper 1995:16, Department of Economics, Uppsala University.

Assarsson, B. and P. Jansson (1996), "Unemployment persistence: the Case of Sweden", forthcoming in Applied Economics Letters.

Ball, L. (1996), "Disinflation and the NAIRU", NBER Working Paper 5520.

Blanchard, O. and L.F. Katz (1997), "What we know and do not know about the natural rate of unemployment", Journal of Economic Perspectives 11, 51-72.

Blanchard, O. and D. Quah (1989), "The dynamic effects of aggregate demand and supply disturbances", American Economic Review 79, 655-73.

Clark, P.K. (1989), "Trend reversion in real output and unemployment", Journal of Econometrics 40, 15-32.

Cochrane, J.H. (1994), "Permanent and transitory components of GNP and stock prices", Quarterly Journal of Economics 61, 241-65.

Côté, D. and D. Hostland (1994), "Measuring potential output and the NAIRU as unobserved variables in a systems framework", in Economic Behaviour and Policy Choice under Price Stability, Bank of Canada, 357-418. 
DeSerres, A., A. Guay, and P. St-Amant (1995), "Estimating and projecting potential output using structural VAR methodology: the case of the Mexican economy", Working Paper 95-2, Bank of Canada.

Dolado, J.J. and J.D. López-Salido (1996), "Hysteresis and economic fluctuations", CEPR Discussion Paper No. 1334.

Elmeskov, J. (1993), "High and persistent unemployment: Assessment of the problem and its causes", Working Paper No. 132, Economics Department, OECD.

Engle, R.F. (1978), "Estimating structural models of seasonality", in A. Zellner (ed.), Seasonal Analysis of Economic Time Series, Washington D.C., Department of Commerce, Bureau of the Census, 281-308.

Friedman, M. (1968), "The role of monetary policy", American Economic Review 58, 1-17.

Galí, J. (1992), "How well does the IS-LM model fit postwar U.S. data?", Quarterly Journal of Economics 107, 709-38.

Gerlach, S. and F. Smets (1997), "Output gaps and inflation: Unobservable-components estimates for the G-7 countries", Unpublished paper, Bank for International Settlements.

Giorno, C., P. Richardson, D. Roseveare, and P. van den Noord (1995), "Estimating potential output, output gaps and structural budget balances", Working Paper No. 152, Economics Department, OECD.

Gordon, R.J. (1997), "The time-varying NAIRU and its implications for economic policy", Journal of Economic Perspectives 11, 11-32. 
Hamilton, J.D. (1994), Time Series Analysis, Princeton University Press, Princeton, New Jersey.

Harvey, A.C. (1985), "Trends and cycles in macroeconomic time series", Journal of Business and Economic Statistics 3, 216-27.

Harvey, A.C. and A. Jaeger (1993), "Detrending, stylized facts and the business cycle", Journal of Applied Econometrics, 8, 231-47.

Harvey, A.C. and P.H.J. Todd (1983), "Forecasting economic time series with structural and Box-Jenkins models: A case study" (with discussion), Journal of Business and Economics Statistics 1, 299-315.

Hodrick, R.J. and E.C. Prescott (1981), "Post-war U.S. business cycles: An empirical investigation", Carnegie Mellon University Discussion Paper No. 451.

Hodrick, R.J. and E.C. Prescott (1997), "Post-war U.S. business cycles: An empirical investigation", Journal of Money, Credit, and Banking 29, 1-16.

Jacobson, T., A. Vredin, and A. Warne (1996), "Common trends and hysteresis in Scandinavian unemployment", forthcoming in European Economic Review.

Jaeger, A. (1994), "Mechanical detrending by Hodrick-Prescott filtering: a note", Empirical Economics 19, 493-500.

Jaeger, A. and M. Parkinson (1990), "Testing for hysteresis in unemployment: An unobserved components approach", Empirical Economics 15, 185-98. 
Jaeger, A. and M. Parkinson (1994), "Some evidence on hysteresis in unemployment rates", European Economic Review 38, 329-42.

King, R.G., C.I. Plosser, J.H. Stock, and M.W. Watson (1991), "Stochastic trends and economic fluctuations", American Economic Review 81, 819-40.

King, R.G., J.H. Stock, and M.W. Watson (1995), "Temporal instability of the unemployment-inflation relationship", Economic Perspectives, Federal Reserve Bank of Chicago, 2-12.

King, R.G. and S.T. Rebelo (1993), "Low frequency filtering and real business cycles", Journal of Economic Dynamics and Control 17, 207-231.

Kuttner, K.N. (1991), "Using noisy indicators to measure potential output", Working Paper 1991-14, Research Department, Federal Reserve Bank of Chicago.

Kuttner, K.N. (1994), "Estimating potential output as a latent variable", Journal of Business and Economic Statistics 12, 361-68.

Laxton, D. and R. Tetlow (1992), "A simple multivariate filter for the measurement of potential output", Technical Report No. 59, Bank of Canada.

Lindblad, H. (1997), "Persistence in Swedish unemployment rates", Working Paper 1997:3, Department of Economics, University of Stockholm.

Okun, A.M. (1962), "Potential GNP: Its measurement and significance", in Proceedings of the Business and Economics Section, American Statistical Association, Washington D.C., 98-104. 
Phelps, E.S. (1967), "Phillips curves, expectations of inflation and optimal unemployment over time", Economica 34, 254-81.

Shapiro, M.D. and M.W. Watson (1988), "Sources of business cycle fluctuations", in S. Fischer (ed.), NBER Macroeconomic Annual, MIT Press, 111-48.

Sims, C.A. (1980), "Macroeconomics and reality", Econometrica 48, 1-48.

Solow, R.M. (1956), "A contribution to the theory of economic growth", Quarterly Journal of Economics 70, 65-94.

Staiger, D., J.H. Stock, and M.W. Watson (1996), "How precise are estimates of the natural rate of unemployment?", NBER Working Paper 5477.

St-Amand, P. and S. van Norden (1996), "An overview of recent research at the Bank of Canada on the measurement of potential output and the output gap", Unpublished paper, Bank of Canada.

Watson, M.W. (1986), "Univariate detrending methods with stochastic trends", Journal of Monetary Economics 18, 49-75.

Watson, M.W. and R.F. Engle (1983), "Alternative algorithms for the estimations of dynamic factor, MIMIC and varying coefficient regression", Journal of Econometrics 23, 385400. 